\title{
THE
}

\section{Dose Ranging and Fractionation of Intravenous Ciprofloxacin against Pseudomonas aeruginosa and Staphylococcus aureus in an In Vitro Model of Infection}

\author{
C. Randall Marchbanks \\ University of Rhode Island \\ R. McKiel \\ University of Rhode Island \\ Deborah H. Gilbert \\ University of Rhode Island \\ Norman J. Robillard \\ Barbara Painter
}

See next page for additional authors

Follow this and additional works at: https://digitalcommons.uri.edu/php_facpubs

Terms of Use

All rights reserved under copyright.

\section{Citation/Publisher Attribution}

Marchbanks, C. R., McKiel, J. R., Gilbert, D. H., Robillard, N. J., Painter, B., Zinner, S. H., \& Dudley, M. N.

(1993). Dose Ranging and Fractionation of Intravenous Ciprofloxacin against Pseudomonas aeruginosa

and Staphylococcus aureus in an In Vitro Model of Infection. Antimicrob. Agents Chemother., 37(9),

1756-1763. doi: 10.1128/AAC.37.9.1756.

Available at: http://dx.doi.org/10.1128/AAC.37.9.1756

This Article is brought to you for free and open access by the Pharmacy Practice at DigitalCommons@URI. It has been accepted for inclusion in Pharmacy Practice Faculty Publications by an authorized administrator of DigitalCommons@URI. For more information, please contact digitalcommons-group@uri.edu. 


\section{Authors}

C. Randall Marchbanks, R. McKiel, Deborah H. Gilbert, Norman J. Robillard, Barbara Painter, Stephen H. Zinner, and Michael N. Dudley

This article is available at DigitalCommons@URI: https://digitalcommons.uri.edu/php_facpubs/110 


\title{
Dose Ranging and Fractionation of Intravenous Ciprofloxacin against Pseudomonas aeruginosa and Staphylococcus aureus in an In Vitro Model of Infection
}

\author{
C. RANDALL MARCHBANKS, ${ }^{1}$ JOAN R. MCKIEL, ${ }^{1}$ DEBORAH H. GILBERT, ${ }^{1}$ NORMAN J. ROBILLARD, ${ }^{2}$ \\ BARBARA PAINTER, ${ }^{2}$ STEPHEN H. ZINNER, ${ }^{3,4}$ AND MICHAEL N. DUDLEY ${ }^{1 *}$ \\ Antiinfective Pharmacology Research Unit, University of Rhode Island College of Pharmacy, ${ }^{1}$ and Division of \\ Infectious Disease, Brown University ${ }^{3}$ and Roger Williams Medical Center, Providence, Rhode Island 02908, \\ and Pharmaceutical Division, Miles Inc., West Haven, Connecticut $06516^{2}$
}

Received 8 September 1992/Returned for modification 5 January 1993/Accepted 21 May 1993

\begin{abstract}
The effect of dose or dose interval on the pharmacodynamics of simulated high-dose intravenous ciprofloxacin therapy on infection due to Pseudomonas aeruginosa and Staphylococcus aureus was studied in an in vitro hollow-fiber model of infection. Simulated doses of $1,200 \mathrm{mg}$ of ciprofloxacin per day as either $400 \mathrm{mg}$ every $8 \mathrm{~h}$ or $600 \mathrm{mg}$ every $12 \mathrm{~h}$ against $P$. aeruginosa resulted in selection of ciprofloxacin-resistant bacteria. The results with one test strain that was isolated from a patient prior to administration of intravenous ciprofloxacin demonstrated selection of a gyrA mutant in the model, as had occurred in vivo. A single 1,200-mg dose every $24 \mathrm{~h}$ did not select for bacterial resistance; however, breakthrough regrowth of ciprofloxacinsusceptible bacteria occurred. Dosages of 400 or $600 \mathrm{mg}$ of ciprofloxacin every $12 \mathrm{~h}$ effectively reduced bacterial counts of one strain each of methicillin-susceptible or -resistant $S$. aureus, with no bacterial resistance detected at the end of experiment; in contrast, $200 \mathrm{mg}$ every $12 \mathrm{~h}$ resulted in bacterial regrowth due to the selection of drug-resistant bacteria. These data show the need for high-dose intravenous ciprofloxacin, particularly with regimens producing high peak levels, for treatment of infections where selection for bacterial resistance is a clinical problem.
\end{abstract}

Despite significant clinical experience with ciprofloxacin and other fluoroquinolones, the optimal dose and schedule for treatment remain unknown. Elucidation of the pharmacodynamic variables most predictive of a favorable response leads to the design of optimal dosing regimens. This may be particularly important for infections due to organisms such as Pseudomonas aeruginosa and Staphylococcus aureus, for which the MICs of most fluoroquinolones are at or slightly below the breakpoint for susceptibility and for which selection for bacterial resistance has been associated with failure to respond clinically $(9,12,16-18,21)$.

This study evaluated the effects of various doses and dosing intervals of ciprofloxacin against $P$. aeruginosa and $S$. aureus in an in vitro model of infection. Several pharmacokinetic and pharmacodynamic variables were examined to ascertain those associated with bacterial eradication and suppression of resistant bacterial subpopulations, including strains whose mechanism of resistance had been previously characterized by using specific probes.

\section{MATERIALS AND METHODS}

Bacteria. All bacterial test isolates were provided by N.J.R. Two strains each of $P$. aeruginosa and $S$. aureus were studied. For all strains an inoculum of $\sim 5 \times 10^{5}$ CFU/ml had mode MICs of ciprofloxacin of $1 \mathrm{mg} /$ liter in cation-supplemented Mueller-Hinton broth (MHB-S), as assessed by the tube broth macrodilution method (15). $P$. aeruginosa MP001 is a pretherapy clinical isolate obtained from a patient with mediastinitis and empyema; two ciprofloxacin-resistant gyrA (cfxA) mutants (MP002 and MP003)

\footnotetext{
* Corresponding author.
}

of this strain with ciprofloxacin MICs of 8 and $16 \mathrm{mg} / \mathrm{liter}$, respectively, were isolated from the patient after intravenous ciprofloxacin therapy (12). $P$. aeruginosa PAO2, a well-characterized laboratory strain, was also studied in the model. Selection of ciprofloxacin-resistant mutants on agar containing 2 times the MIC of drug occurs at a frequency of $\sim 10^{-7}(20)$. These isolates had both the $c f x A$ and $c f x B$ chromosomal mutations, alone or combined, as well as changes in outer membrane proteins $(20)$.

Two strains of $S$. aureus were tested. Strain MP1200 is a methicillin-resistant strain of $S$. aureus, and MP1201 is a methicillin-susceptible strain of $S$. aureus.

In vitro model. Hollow-fiber bioreactor chambers (CellPharm Mini-Bioreactor System; CD Medical, Inc., Miami Lakes, Fla.) were connected in series to a central compartment in an incubator as previously described (2). The volume of each peripheral chamber was $15 \mathrm{ml}$. The central compartment diluent was MHB-S; peripheral compartments contained $10 \%$ heat-inactivated human serum plus $90 \%$ MHB-S. Following a dose of ciprofloxacin, the drug was eliminated by pumping drug-free MHB-S into the central compartment at a rate adjusted to simulate the human pharmacokinetics of the drug.

The bacteria used for all experiments were prepared from inocula previously grown, aliquoted, and frozen in a mixture of brain heart infusion broth and fetal calf serum (60:40). On the day of an experiment, the frozen inoculum was thawed, diluted with fresh MHB-S, and incubated for 1 to $2 \mathrm{~h}$ to bring organisms into the log-linear growth phase. The bacteria were then injected into the peripheral compartments of the model and incubated for $2 \mathrm{~h}$ to reach an inoculum of about 2 $\times 10^{6} \mathrm{CFU} / \mathrm{ml}$.

Samples ( 1 to $1.5 \mathrm{ml}$ ) were collected from the central and peripheral compartments over $30 \mathrm{~h}$ and assayed for drug 

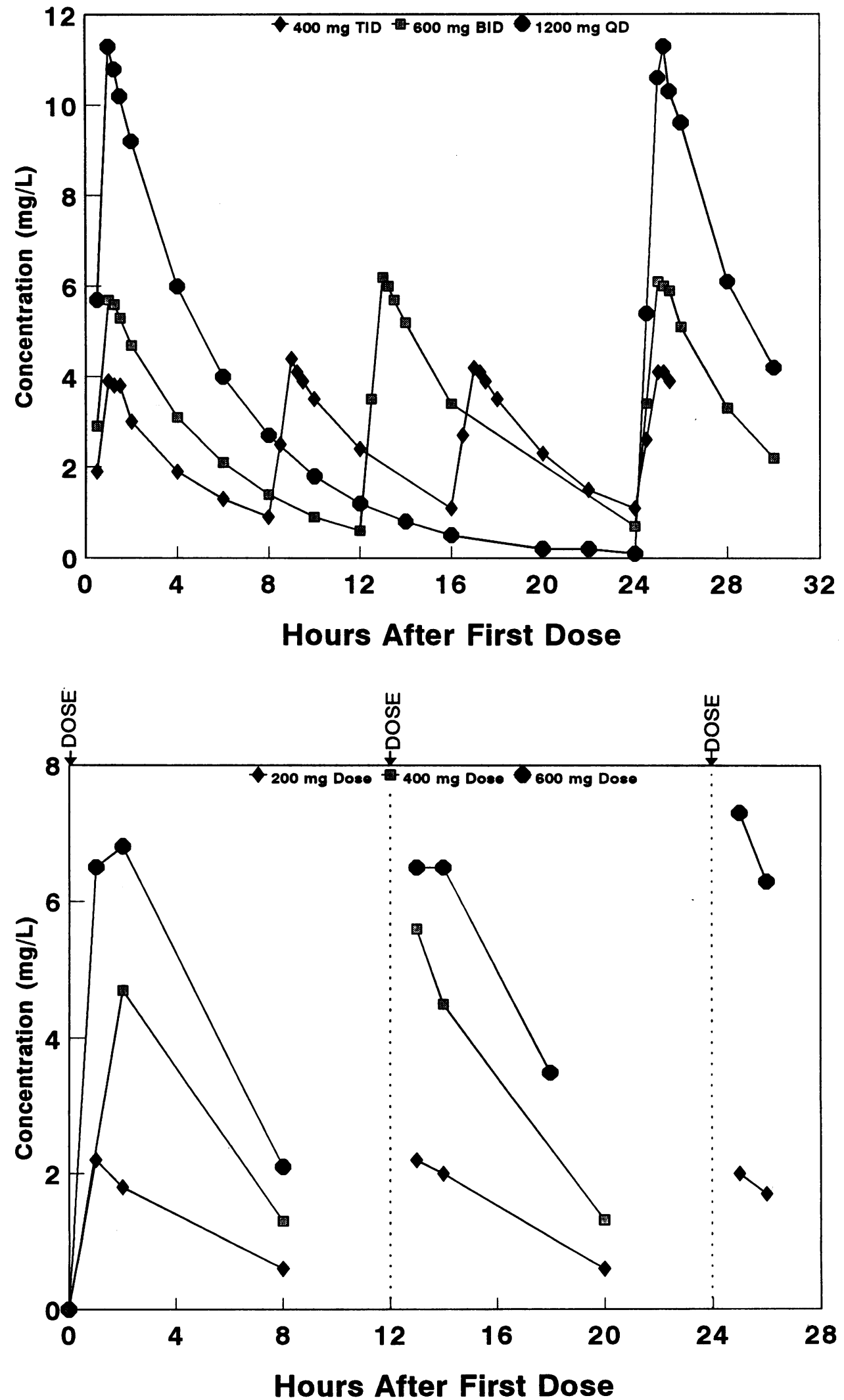

FIG. 1. Ciprofloxacin concentrations measured in the central compartment for the three dosage regimens against both strains of $P$. aeruginosa (top) and $S$. aureus (bottom). TID, every $8 \mathrm{~h}$; BID, every $12 \mathrm{~h}$; QD, every $24 \mathrm{~h}$. 
TABLE 1. Ciprofloxacin pharmacokinetic parameters in the in vitro model relative to the initial MIC, based on measured drug concentrations for different dosage regimens

\begin{tabular}{|c|c|c|c|c|c|c|}
\hline \multirow{2}{*}{$\begin{array}{c}\text { Organism and } \\
\text { regimen }^{a}\end{array}$} & \multirow{2}{*}{ Peak/MIC } & \multirow{2}{*}{$\begin{array}{c}\text { Peak - MIC } \\
\text { (mg/liter) }\end{array}$} & \multicolumn{2}{|c|}{ Time $>\operatorname{MIC}^{d}(\mathrm{~h})$} & \multicolumn{2}{|c|}{ AUC $>$ MIC $^{e}(\mathrm{mg} \cdot \mathrm{h} / \mathrm{liter})$} \\
\hline & & & $0-8 \mathrm{~h}$ & $0-24 \mathrm{~h}$ & $0-8 \mathrm{~h}$ & $0-24 \mathrm{~h}$ \\
\hline \multicolumn{7}{|l|}{ P. aeruginosa } \\
\hline $400 \mathrm{mg}$ TID & 4.2 & 3.2 & 7.5 & 23 & 7.9 & 23 \\
\hline 600 mg BID & 6 & 5 & 8 & 20 & 17 & 38 \\
\hline $1,200 \mathrm{mg} Q D$ & 11 & 10 & 8 & 13 & 40 & 43 \\
\hline \multicolumn{7}{|l|}{ S. aureus } \\
\hline $200 \mathrm{mg}$ BID & 2.2 & 1.2 & 5 & 10 & 2.3 & 4.7 \\
\hline 400 mg BID & 5.9 & 4.9 & 8 & 18 & 18.3 & 35.4 \\
\hline $600 \mathrm{mg}$ BID & 6.8 & 5.8 & 8 & 24 & 28.6 & 62.8 \\
\hline
\end{tabular}

a TID, every $8 \mathrm{~h}$; BID, every $12 \mathrm{~h}$; QD, every $24 \mathrm{~h}$.

${ }^{b}$ Ratio of peak drug concentration to MIC.

${ }^{c}$ Difference between peak drug concentration and MIC.

${ }^{d}$ Time that ciprofloxacin concentration exceeded the MIC.

e Area under the ciprofloxacin concentration-time curve that exceeded the MIC.

(central and peripheral chambers) and bacterial (peripheral chambers) concentrations. Ciprofloxacin concentrations in samples from experiments with $P$. aeruginosa were measured by high-pressure liquid chromatography (HPLC) (10). Bioassay by a previously described method was used to measure drug concentrations in the central compartment in experiments with $S$. aureus (6). The between-day variability and accuracy of the HPLC and bioassay methods were $<10 \%$.

Bacteria were quantified by placing samples serially diluted in cold saline on drug-free Mueller-Hinton agar (MHA) plates, incubating at $37^{\circ} \mathrm{C}$, and counting colonies. Samples with very low numbers of bacteria were placed in $10 \mathrm{ml}$ of cold saline and then filtered with a $0.45-\mu \mathrm{m}$ filter (Millipore Corporation, Bedford, Mass.). The filter was then placed directly on drug-free MHA and incubated. The limit of detection by this method was $10 \mathrm{CFU} / \mathrm{ml}$.

Dosage regimens and pharmacokinetics. Initial experiments were conducted with a fixed daily exposure of $1,200 \mathrm{mg}$ of ciprofloxacin given as $600 \mathrm{mg}$ every $12 \mathrm{~h}$. Subsequent reduction or fractionation of the total daily dose was based on results with this regimen; if divided doses of $600 \mathrm{mg}$ every $12 \mathrm{~h}$ effectively reduced bacterial CFU per milliliter with no regrowth due to selection of resistant bacteria, the daily exposure would be lowered to $400 \mathrm{mg}$ every $12 \mathrm{~h}$ and then to $200 \mathrm{mg}$ every $12 \mathrm{~h}$ until a dose resulting in no net bacterial killing by $24 \mathrm{~h}$ was reached. If bacterial regrowth and/or resistance occurred following the initial regimen of $600 \mathrm{mg}$ every $12 \mathrm{~h}$, the total daily dose was fractionated as either 400 mg every $8 \mathrm{~h}$ or $1,200 \mathrm{mg}$ every $24 \mathrm{~h}$. Doses were given as 60 -min constant-rate infusions. The elimination half-life of ciprofloxacin in the model was adjusted to $3.5 \mathrm{~h}$ (7).

Pharmacokinetic and pharmacodynamic parameters for each regimen were calculated by using measured ciprofloxacin concentrations in the central compartment and pretreatment MICs. Previous studies with these bioreactor units showed rapid equilibration of drug between the compartments. This allows one to focus on exposure profiles in the analogous "intravascular" compartment. The parameters calculated included the relation of the peak drug concentration to the MIC as either a ratio or a difference, the time that the ciprofloxacin concentration exceeded the MIC, and the area under the ciprofloxacin concentration-time curve that exceeded the MIC (5).

Drug resistance. Samples taken prior to drug exposure (time zero) and at $24 \mathrm{~h}$ were placed on MHA plates contain- ing no drug or $0.5,1$, or $4 \mathrm{mg}$ of ciprofloxacin per liter to quantify ciprofloxacin-resistant bacterial subpopulations. The MICs for post-treatment isolates recovered on drug-free plates also were determined by broth macrodilution.

Eight isolates of $P$. aeruginos $a$ recovered from the model on ciprofloxacin-containing or drug-free plates prior to or 24 $\mathrm{h}$ after the first drug dose were probed for a $g y r A$ mutation by using a broad-host-range gyrase A gene probe (19). This probe, pNJR3-2, consists of an Escherichia coli gyrase A gene cloned into the cosmid vector pLA2917. Previous studies of matings of NJR3-2 into resistant mutants of MP001 (selected during therapy) and PAO2 showed that it is capable of restoring pure gyrA (i.e., $c f x A$ ) mutants to wild-type susceptibility. The probe has no effect on fully susceptible or $c f x B$ mutants and only partially restores susceptibility of $c f x A c f x B$ double mutants of PAO2 (19).

Isolates recovered on drug-containing plates were passed three times on plates containing the same concentration of ciprofloxacin and once onto drug-free MHA and then transferred onto a Trypticase soy agar slant for transport and storage for probe studies. Bacterial isolates recovered on drug-free plates were passed one or two times on drug-free MHA and then transferred onto a Trypticase soy agar slant. In addition, several isolates were frozen in glycerol for longer-term storage prior to probe studies. Bacterial isolates recovered from the model were incubated with $E$. coli S17-1 containing the vector plasmid pLA2917 (negative control) or pNJR3-2 overnight in broth, and passed onto Pseudomonas isolation medium as previously described (19). A known $c f x A$ mutant of $\mathrm{PAO} 2$ was used as a positive control. An isolate demonstrating an increase in ciprofloxacin susceptibility following exposure to the probe relative to that of the pretreatment isolate was judged to have a pure gyr $A$ mutation.

\section{RESULTS}

Pharmacokinetics. Figure 1 depicts ciprofloxacin concentrations in the central compartment of the model for the three dosage regimens tested against each strain. Drug concentrations in samples collected simultaneously from the central and all peripheral chambers of the model were with 10 to $15 \%$ of each other; thus, concentrations in the central compartment were used in pharmacokinetic-pharmacodynamic calculations. Pharmacokinetic parameters related to the MIC are shown in Table 1 . As would be expected, the 

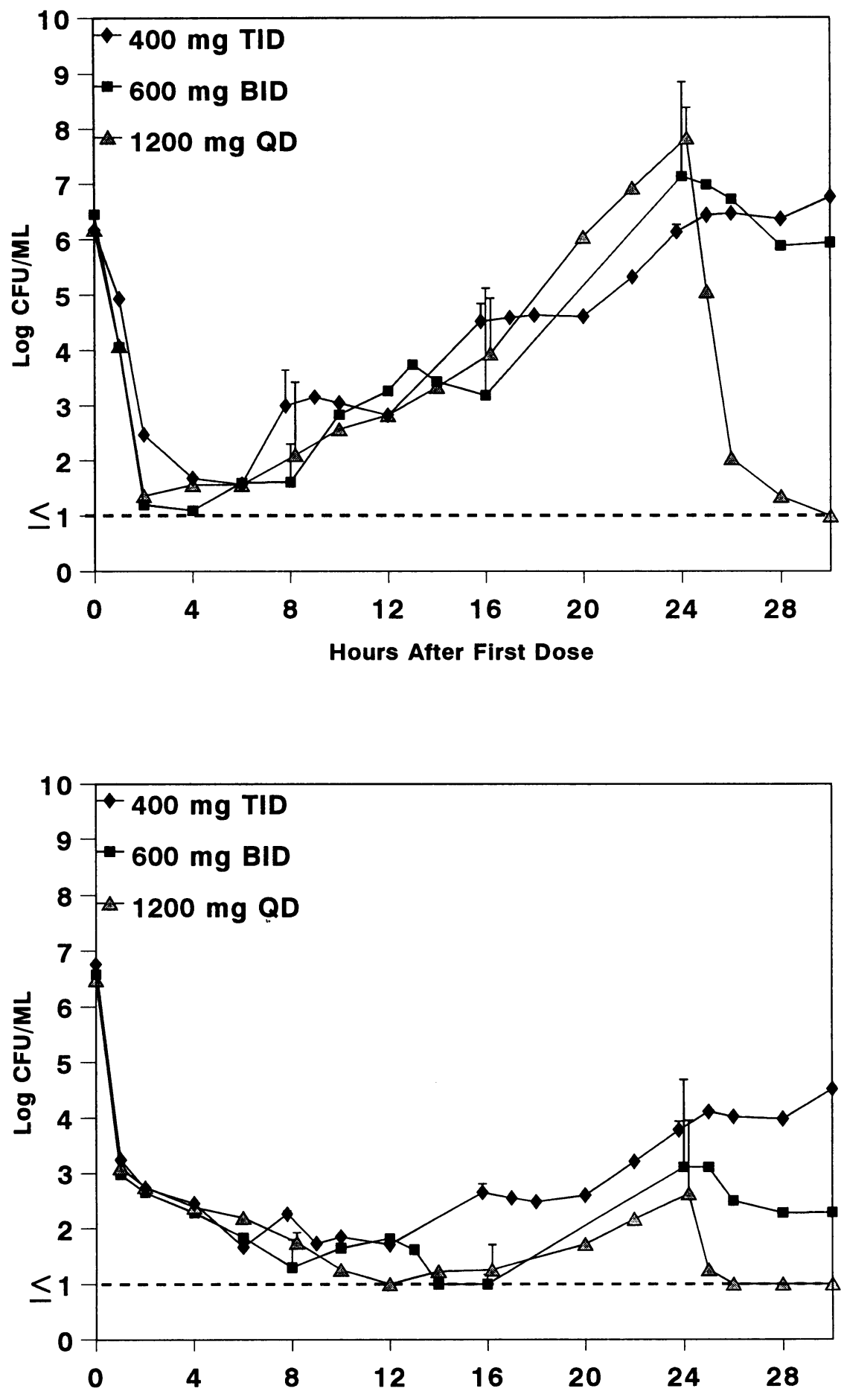

Hours After First Dose

FIG. 2. Pharmacodynamics of ciprofloxacin for three different dosage regimens against $P$. aeruginosa MP001 (top) and $P$. aeruginosa PAO2 (bottom). Datum points are geometric means plus standard deviations for three replicate chambers. For abbreviations, see the legend to Fig. 1.

ratio of and difference between the peak concentration and MIC increased, the area under the curve that exceeded the MIC increased, and the time that the concentration exceeded the MIC decreased as dose size (and interval) increased. With the regimen of $400 \mathrm{mg}$ every $8 \mathrm{~h}$, ciprofloxacin concentrations essentially always exceeded the initial MIC $(1 \mathrm{mg} /$ liter) for both strains. With the regimens of $600 \mathrm{mg}$ every $12 \mathrm{~h}$ and $1,200 \mathrm{mg}$ every $24 \mathrm{~h}$, drug concentrations exceeded the initial MIC for only 80 and $54 \%$ of the dosing interval, respectively. 

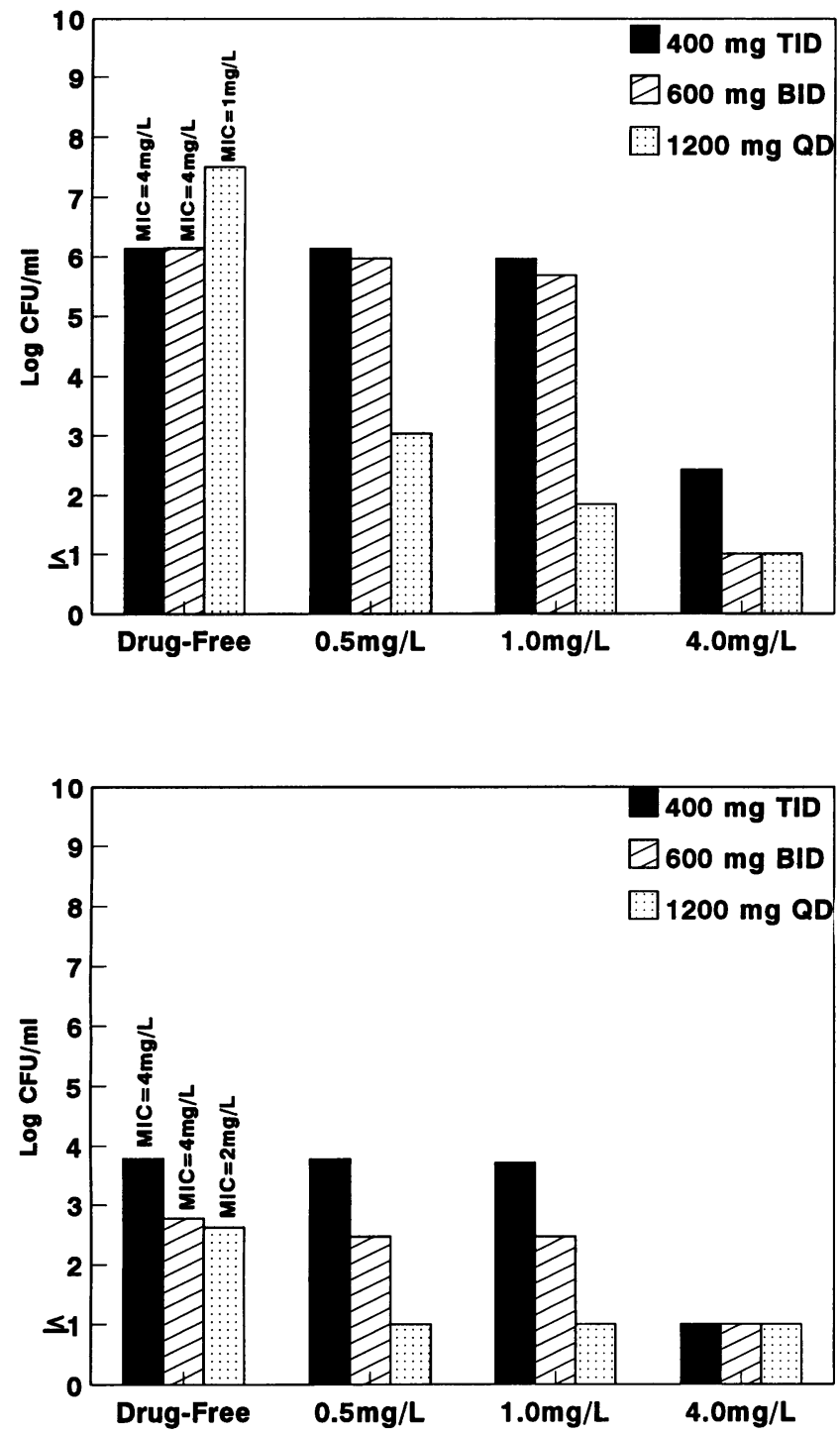

FIG. 3. Recovery of $P$. aeruginosa MP001 (top) and $P$. aeruginosa PAO2 (bottom) on MHA containing no drug or $0.5,1.0$, or 4.0 $\mathrm{mg}$ of ciprofloxacin per liter. Organisms were recovered at $24 \mathrm{~h}$ following exposure to three different ciprofloxacin dosage regimens. The broth MICs for organisms recovered on drug-free plates are also shown. For abbreviations, see the legend to Fig. 1.

Experiments with $S$. aureus utilized a fixed 12-h dosing interval; thus, changes in parameters were proportional to dose size (Table 1). With the 200-mg dose, the concentration exceeded the MIC for only $5 \mathrm{~h}$ of the 12-h dosing interval, whereas the 400 - and $600-\mathrm{mg}$ doses produced concentrations which exceeded the MIC for cumulative periods of 18 and 24 $h$, respectively, of a 24-h interval. The area under the curve that exceeded the MIC was severalfold higher for the 400 and $600-\mathrm{mg}$ doses relative to the $200-\mathrm{mg}$ dose.

Pharmacodynamics and bacterial resistance. (i) $P$. aeruginosa. The first dose with all regimens resulted in a marked bactericidal effect (about a 5-log reduction in CFU per milliliter) over the first $4 \mathrm{~h}$ in both strains (Fig. 2). With strain MP001, regrowth occurred before the second dose with all regimens; bacterial counts returned to the level of the initial inoculum by $24 \mathrm{~h}$ despite subsequent doses with the regi- mens of $400 \mathrm{mg}$ every $8 \mathrm{~h}$ and $600 \mathrm{mg}$ every $12 \mathrm{~h}$ (Fig. 2, top). In contrast, the subsequent $1,200-\mathrm{mg}$ dose given at $24 \mathrm{~h}$ resulted again in marked killing of this strain.

A similar but less pronounced pattern was observed with strain PAO2; initial killing with the regimens of $400 \mathrm{mg}$ every $8 \mathrm{~h}$ and $600 \mathrm{mg}$ every $12 \mathrm{~h}$ was followed by bacteriostasis and slight regrowth with subsequent doses (Fig. 2, bottom). However, the second $1,200-\mathrm{mg}$ dose with the regimen of $1,200 \mathrm{mg}$ every $24 \mathrm{~h}$ exerted a marked bactericidal effect against this strain; this was also observed in strain MP001.

The susceptibility of bacteria recovered at $24 \mathrm{~h}$ following exposure to $400 \mathrm{mg}$ every $8 \mathrm{~h}$ or $600 \mathrm{mg}$ every $12 \mathrm{~h}$ demonstrated that the majority of organisms were resistant to $1 \mathrm{mg}$ of ciprofloxacin per liter (Fig. 3); for strain MP001, a small proportion was resistant to $4 \mathrm{mg} /$ liter. The ciprofloxacin MIC (in MHB-S) for bacteria recovered on the drug-free plate was $4 \mathrm{mg} /$ liter. In contrast to the every-8- or $-12-\mathrm{h}$ regimens, subpopulation analysis with the regimen of 1,200 mg every $24 \mathrm{~h}$ revealed that either only a small proportion of the inoculum was resistant to $1 \mathrm{mg}$ of ciprofloxacin per liter (strain MP001; Fig. 3, top) or all organisms remained susceptible to $1 \mathrm{mg} /$ liter (strain PAO2; Fig. 3, bottom). The MIC in MHB-S for bacteria recovered on drug-free medium following the single large dose did not change for strain MP001 and increased only slightly (from 1 to $2 \mathrm{mg}$ /liter) for strain PAO2.

DNA gene probe analysis of isolates from both strains of $P$. aeruginosa at $24 \mathrm{~h}$ showed selection of pure gyrA mutants only in strain MP001. These mutants were recovered on the drug-free plate following the regimen of $600 \mathrm{mg}$ every $12 \mathrm{~h}$. In the other case they were detected in one of the three distinct colony morphology types tested from a plate containing $0.5 \mathrm{mg}$ of ciprofloxacin per liter following the regimen of $1,200 \mathrm{mg}$ every $24 \mathrm{~h}$. No pure gyrA mutants were detected with the regimen of $400 \mathrm{mg}$ every $8 \mathrm{~h}$ against this strain or with any regimen with strain $\mathrm{PAO} 2$, indicating that changes in susceptibility were of the $c f x B$ type or perhaps were double mutations.

(ii) S. aureus. Dosing of 400 or $600 \mathrm{mg}$ of ciprofloxacin every $12 \mathrm{~h}$ resulted in rapid and complete killing of both strains of $S$. aureus, with no selection for ciprofloxacinresistant bacteria during the experiment (Fig. 4, top). However, with the regimen of $200 \mathrm{mg}$ every $12 \mathrm{~h}$, an initial 4- to 5-log kill was followed by bacterial regrowth within $10 \mathrm{~h}$ after the first dose for both strains (Fig. 4, bottom). The second $200-\mathrm{mg}$ dose at $12 \mathrm{~h}$ produced some bacterial killing but was followed by sustained bacterial regrowth; the final dose at 24 $h$ had no significant effect on bacterial counts.

Analysis of isolates of both strains at $24 \mathrm{~h}$ following the regimen of $200 \mathrm{mg}$ every $12 \mathrm{~h}$ revealed bacterial subpopulations resistant to $1 \mathrm{mg}$ of ciprofloxacin per liter (Fig. 5); a small proportion of the inoculum of the methicillin-resistant strain was also resistant to $4 \mathrm{mg}$ of ciprofloxacin per liter. A fourfold rise in MIC in MHB-S (from 1 to $4 \mathrm{mg} /$ liter) for bacteria recovered on drug-free plates was observed for both strains. The basis of increased resistance in these strains was not investigated.

\section{DISCUSSION}

Although the fluoroquinolones have been established as effective agents in the treatment of a number of infections, bacterial resistance has limited their usefulness in serious infections due to certain organisms. Among gram-negative bacteria, $P$. aeruginosa has often been associated with changes in susceptibility to ciprofloxacin following therapy 

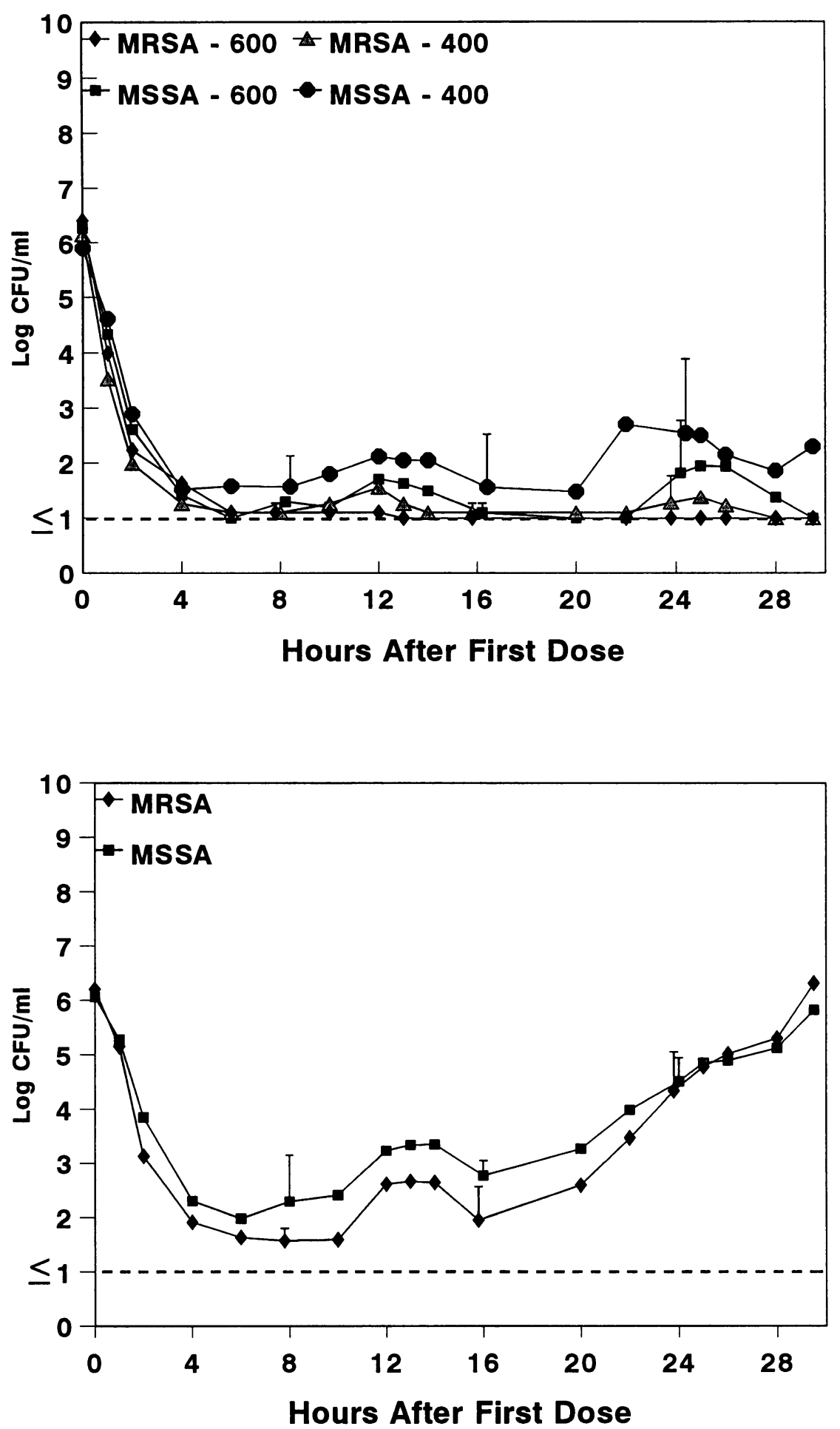

FIG. 4. Pharmacodynamics of ciprofloxacin following 400 or $600 \mathrm{mg}$ every $12 \mathrm{~h}$ (top) and $200 \mathrm{mg}$ every $12 \mathrm{~h}$ (bottom) against a methicillin-susceptible (MSSA) and a methicillin-resistant (MRSA) strain of $S$. aureus. Datum points are geometric means plus standard deviations for three replicate chambers.

$(12,14,16,21,22)$; this has been a particular problem with intravenous dosage regimens of 200 to $300 \mathrm{mg}$ twice daily (6, 17). The mechanism of resistance in gram-negative bacilli seems to be of two types. Alterations in DNA gyrase (gyrA mutation) occur at a frequency of $10^{-7}$ and are associated with a 4- to 16-fold increase in the MIC compared with that for wild-type strains (22). Bacteria may also develop changes in outer membrane permeability to ciprofloxacin, thus limiting access of the drug to the cytoplasmic target site (3). Resistance of methicillin-susceptible and -resistant strains of 


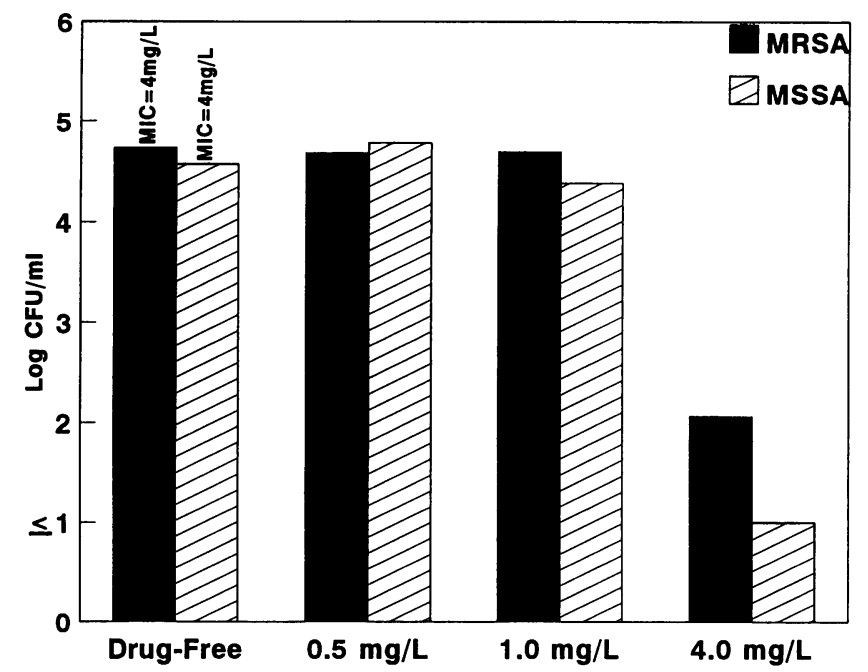

FIG. 5. Recovery of $S$. aureus on agar plates containing no drug or $0.5,1.0$, or $4.0 \mathrm{mg}$ of ciprofloxacin per liter from two replicate chambers. Organisms tested were those recovered at $24 \mathrm{~h}$ following exposure to $200 \mathrm{mg}$ of ciprofloxacin every $12 \mathrm{~h}$. The broth MICs for organisms recovered on drug-free plates are also shown. For abbreviations, see the legend to Fig. 4.

$S$. aureus to ciprofloxacin and other fluoroquinolones is an increasing problem which has limited the use of these agents in the treatment of serious infections due to these organisms $(13,20)$.

In view of the clinical problem of bacterial resistance with fluoroquinolone therapy of infection due to these species, we studied the role of pharmacokinetics in the selection of resistance. The dosage regimens tested higher simulated levels of exposure of ciprofloxacin than have been studied systematically to date in humans. Our studies included experiments with isolates of $P$. aeruginosa whose genotypic and phenotypic bases for resistance following exposure to ciprofloxacin were previously well characterized. One of the strains tested in our model was a pretherapy isolate recovered from a patient whose failure to respond to intravenous ciprofloxacin therapy was proven to be due to selection of a drug resistant $g y r A$ mutant of the same strain $(12,16)$. Studies using the model with the pretherapy isolate of this strain (M0001) showed that a high-dose regimen of $1,200 \mathrm{mg}$ of ciprofloxacin per day given as either $400 \mathrm{mg}$ every $8 \mathrm{~h}$ or $600 \mathrm{mg}$ every $12 \mathrm{~h}$ resulted in the selection of ciprofloxacinresistant bacteria with a $g y r A$ mutation, as had been described previously for this organism (12). While the scope of comparisons is indeed limited, these data suggest that the endpoints observed in the in vitro model for a dosage regimen may forecast the response to human infection with a similarly large bacterial inoculum (5).

The killing of $P$. aeruginosa by ciprofloxacin was initially rapid and then slow prior to regrowth due to bacterial resistance (2). This biphasic killing pattern has been noted previously in experiments using static concentrations of drug $(4,23)$. Although adaptive resistance has not been described for fluroquinolones, Wolfson et al. have described selection of partially tolerant mutants of $E$. coli in vitro following exposure to norfloxacin (23).

Although bacterial regrowth was observed within 6 to $8 \mathrm{~h}$ with all of the dosage regimens for $P$. aeruginosa, the regrowth that occurred following exposure to a single 1,200-mg dose was due not to ciprofloxacin-resistant bacteria but to breakthrough growth of susceptible bacteria. This was evident by the marked bactericidal effect of a subsequent dose given at $24 \mathrm{~h}$. Therefore, for these strains of $P$. aeruginosa, exposure to $1,200 \mathrm{mg}$ of ciprofloxacin per day given as any regimen in the model was incapable of preventing the selection of drug-resistant bacteria or causing a net reduction of bacterial counts over a $24-\mathrm{h}$ period. Bacterial regrowth occurred because of selection of ciprofloxacinresistant bacteria with regimens using more frequent dosing ( $400 \mathrm{mg}$ every $8 \mathrm{~h}$ or $600 \mathrm{mg}$ every $12 \mathrm{~h}$ ) or survival of small numbers of ciprofloxacin-susceptible bacteria which persisted and regrew with the regimen of $1,200 \mathrm{mg}$ every $24 \mathrm{~h}$ during prolonged periods of low concentrations of drug.

Studies with a methicillin-susceptible and a methicillinresistant strain of $S$. aureus demonstrated the rapid selection of resistance to ciprofloxacin with the low dosage $(200 \mathrm{mg}$ every $12 \mathrm{~h}$ ) but not with the regimens of 400 or $600 \mathrm{mg}$ every $12 \mathrm{~h}$. Whether these higher-dosage regimens will result in a reduced frequency of resistance when continued over a longer period of exposure (as is the case with treatment of human infection) clearly requires further study.

Although previous studies of fluoroquinolones against gram-negative bacteria in in vitro $(1,6)$ and animal $(8,11)$ models of infection and in humans (15) have examined the relation between certain pharmacokinetic parameters and outcomes, the results from these studies have at times appeared to conflict with each other. However, the apparent discrepancies between studies are often resolved when one considers differences in study design, selection of improper pharmacokinetic models, and use of a large bacterial inoculum to measure the selection of bacterial resistance as an endpoint (5). However, the weight of evidence indicates that high peak concentrations relative to the MIC is the parameter associated with improved outcome, particularly when selection for bacterial resistance leads to failure in clinical or experimental infection $(1,4,8)$. As with previous studies with fluoroquinolones in this model, peak concentration/ MIC ratios of less than 10 were associated with selection of drug-resistant populations of $P$. aeruginosa $(1,6)$. The finding that shorter dosage intervals with a fixed dosage level result in lower, sustained drug levels closer to the MIC is not surprising, since these regimens most closely resemble laboratory procedures to select for drug-resistant mutants in vitro.

The data from the current study show the importance of high-dose therapy resulting in a increased exposure of bacteria to ciprofloxacin during the early stages of therapy (e.g., the first $8 \mathrm{~h}$ ) for the suppression of ciprofloxacin-resistant bacteria. Our system is set up to test the worst-case example, in which no host defenses are present, and results when intact host defenses are present may be different. Further studies evaluating the safety and efficacy of higher doses in humans are required.

\section{ACKNOWLEDGMENTS}

The assistance of George Kroll with the HPLC assay of ciprofloxacin samples and of Chris Neumann with helpful discussions is acknowledged.

This work was supported in part by a grant from Miles Pharmaceuticals, West Haven, Conn.

\section{REFERENCES}

1. Blaser, J., B. B. Stone, M. C. Groner, and S. H. Zinner. 1987. Comparative study with enoxacin and netilmicin in a pharmacodynamic model to determine importance of ratio of antibiotic 
peak concentration to MIC for bacterial activity and emergence of resistance. Antimicrob. Agents Chemother. 31:1054-1060.

2. Blaser, J., B. B. Stone, and S. H. Zinner. 1985. Two compartment kinetic model with multiple artificial capillary units. J. Antimicrob. Chemother. 15(Suppl. A):131-137.

3. Daikos, G. L., V. T. Lolans, and G. G. Jackson. 1988. Alterations in outer membrane proteins of Pseudomonas aeruginosa associated with selective resistance to quinolones. Antimicrob. Agents Chemother. 32:785-787.

4. Dudley, M. N. 1991. Pharmacodynamics and pharmacokinetics of antibiotics with special reference to the fluoroquinolones. Am. J. Med. 91(Suppl. 6A):45S-50S.

5. Dudley, M. N. 1992. Commentary on dual individualization with antibiotics, p. 18-1-18-13. In W. E. Evans, J. J. Schentag, and W. Jusko (ed.), Applied pharmacokinetics, 3rd ed. Applied Therapeutics, Vancouver, Wash.

6. Dudley, M. N., J. Blaser, D. Gilbert, K. H. Mayer, and S. H. Zinner. 1991. Combination therapy with ciprofloxacin plus azlocillin against Pseudomonas aeruginosa: effect of simultaneous versus staggered administration in an in vitro model of infection. J. Infect. Dis. 164:499-506.

7. Dudley, M. N., J. Ericson, and S. H. Zinner. 1987. Effect of dose on serum pharmacokinetics of intravenous ciprofloxacin with identification and characterization of extravascular compartments using noncompartmental and compartmental pharmacokinetic models. Antimicrob. Agents Chemother. 31:1782-1786.

8. Drusano, G. L., D. E. Johnson, M. Rosen, and H. C. Standiford. 1993. Pharmacodynamics of a fluoroquinolone antimicrobial agent in a neutropenic rat model of Pseudomonas sepsis. Antimicrob. Agents Chemother. 37:483-490.

9. Eron, L. J., L. Harvey, D. L. Hixon, and D. M. Poretz. 1985 Ciprofloxacin therapy of infection caused by Pseudomonas aeruginosa and other resistant bacteria. Antimicrob. Agents Chemother. 27:308-310.

10. Kroll, G. J., A. J. Noe, and D. Beerman. 1986. Liquid chromatographic analysis of ciprofloxacin and ciprofloxacin metabolites in body fluids. J. Liq. Chromatogr. 9:2857-2919.

11. Leggett, J. E., S. Ebert, B. Fantin, and W. A. Craig. 1991 Comparative dose-effect relations at several dosing intervals for beta-lactam, aminoglycoside and quinolone antibiotics against gram-negative bacilli in murine thigh infection and pneumonitis models. Scand. J. Infect. Dis 74(Suppl.):179-184.

12. Masecar, B. L., R. A. Celesk, and N. J. Robillard. 1990. Analysis of acquired ciprofloxacin resistance in a clinical strain of Pseudomonas aeruginosa. Antimicrob. Agents Chemother. 34: 281-286.
13. Meunier, F., S. H. Zinner, H. Gaya, T. Calandra, C. Viscoli, J. Klastersky, M. Glauser, and the European Organization for Research on Treatment of Cancer International Antimicrobial Therapy Cooperative Group. 1991. Prospective randomized evaluation of ciprofloxacin versus piperacillin plus amikacin for empiric antibiotic therapy of febrile granulocytopenic cancer patients with lymphomas and solid tumors. Antimicrob. Agents Chemother. 35:873-878.

14. Michea-Hamzehpour, M., R. Auckenthaler, P. Regemey, and J. C. Pechere. 1987. Resistance occurring after fluoroquinolone therapy of experimental Pseudomonas aeruginosa peritonitis. Antimicrob. Agents Chemother. 31:1803-1808.

15. National Committee for Clinical Laboratory Standards. 1983. Standard methods for dilution antimicrobial susceptibility tests for bacteria which grow aerobically; tentative standards. Document M7-T. National Committee for Clinical Laboratory Standards, Villanova, $\mathrm{Pa}$.

16. Ogle, J. W., L. B. Reller, and M. L. Vasil. 1988. Development of resistance in Pseudomonas aeruginosa to imipenem, norfloxacin, and ciprofloxacin during therapy: proof provided by typing with a DNA probe. J. Infect. Dis. 157:743-748.

17. Peloquin, C. A., J. J. Cumbo, D. E. Nix, M. F. Sands, and J. J. Schentag. 1989. Evaluation of intravenous ciprofloxacin in patients with nosocomial lower respiratory tract infections. Impact of plasma concentrations, organisms, minimum inhibitory concentration, and clinical condition on bacterial eradication. Arch. Intern. Med. 149:2269-2273.

18. Roberts, C. M., J. Batten, and M. E. Hodson. 1985. Ciprofloxacin-resistant Pseudomonas. Lancet i:1442.

19. Robillard, N. J. 1990. Broad-host-range gyrase A gene probe. Antimicrob. Agents Chemother. 34:1889-1894.

20. Robillard, N. J., and A. L. Scarpa. 1988. Genetic and physiological characterization of ciprofloxacin resistance in Pseudomonas aeruginosa PAO. Antimicrob. Agents Chemother. 32: 535-539.

21. Scully, B. E., H. C. Neu, M. F. Parry, and W. Mandell. 1986. Oral ciprofloxacin therapy of infections due to Pseudomonas aeruginosa. Lancet i:819-822.

22. Wolfson, J. S., and D. C. Hooper. 1989. Bacterial resistance to quinolones: mechanisms and clinical importance. Rev. Infect. Dis. 11:S960-S968.

23. Wolfson, J. S., D. C. Hooper, D. J. Shih, G. L. McHugh, and M. N. Schwartz. 1989. Isolation and characterization of an Escherichia coli strain exhibiting partial tolerance to quinolones. Antimicrob. Agents Chemother. 33:705-709. 